\title{
Validity and Reliability of Turkish Version of the Identification Pain Questionnaire in the Assessment of Neuropathic Pain
}

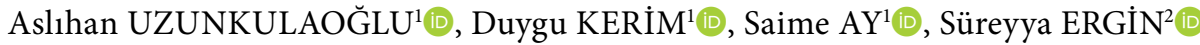 \\ ${ }^{1}$ Department of Physical Medicine and Rehabilitation, Ufuk University Faculty of Medicine, Ankara, Turkey \\ ${ }^{2}$ Department of Physical Medicine and Rehabilitation, Fizyocare Physical Medicine Center, Ankara, Turkey
}

ABSTRACT

Objectives: This study aims to assess the validity and reliability of a Turkish version of the identification (ID) pain (ID pain-T) questionnaire in Turkish patients.

Patients and methods: The Turkish version of ID pain questionnaire was obtained after translation from English into Turkish. The study included

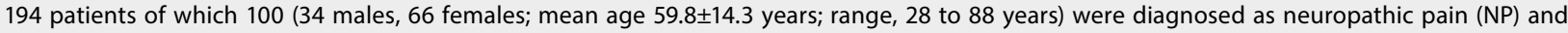
94 (31 males, 63 females; mean age $47.2 \pm 16.5$ years; range, 20 to 78 years) were diagnosed as non-neuropathic pain. Patients with mixed-type pain, cancer pain, headaches, substance abuse, severe depression or fibromyalgia syndrome were excluded.

Results: The reliability and consistency of ID pain-T questionnaire were acceptable, with a Cronbach's alpha coefficient of 0.701 . Statistical analysis of the ID pain-T questionnaire calculated an optimal cut-off score of $\geq 2$ for determining NP with a sensitivity of $77.2 \%$ and a specificity of $85 \%$. Further, with an excellent value of 0.92 for area under the curve, a good diagnostic value was indicated.

Conclusion: The Turkish version of ID pain questionnaire assessed in the present study is a valid and reliable self-administered questionnaire to identify NP in Turkish patients.

Keywords: Identification pain questionnaire; neuropathic pain; outcome measures.

Neuropathic pain (NP) is defined as "pain arising as a direct consequence of a lesion or disease affecting the somatosensory system," by the International Association for the Study of Pain Special Interest Group on Neuropathic Pain. ${ }^{1} \mathrm{NP}$ is a chronic pain disorder caused by a lesion or disease of the somatosensory system and affects millions of people all over the world. ${ }^{1}$ This pain type is different from nociceptive pain (non-neuropathic pain, NNP), having different underlying mechanisms and treatment modalities. ${ }^{2}$ NNP is defined as a type of pain which is generated by the application of stimuli producing damage or injury to somatic or visceral organs, while NP is defined as pain produced by injuries or diseases affecting the somatosensory paths of the peripheral or central nervous system. ${ }^{3-5}$ NP symptoms can be seen as spontaneous or trigger-induced, stabbing, electric shock type, burning, sharp, shooting, pressure, squeezing, deep, aching and cold pain. ${ }^{6,7}$

Neuropathic pain diagnosis is established by clinical examination based on patient history, searching neurologic pathologies and perturbations in sensory functioning. The diagnosis is challenging in many patients and it is difficult to select the appropriate management

Received: July 25, 2018 Accepted: September 28, 2018 Published online: November 30, 2018

Correspondence: Aslıhan Uzunkulaoğlu, MD. Ufuk Üniversitesi Tıp Fakültesi Fiziksel Tıp ve Rehabilitasyon Anabilim Dalı, 06510 Çankaya, Ankara, Turkey. Tel: +90 533 - 5197927 e-mail: aslihanseyrek@gmail.com 
and avoid overdiagnosis. ${ }^{8-10}$ Although specific questionnaires for NP were developed, it is difficult to use such tools routinely in primary care settings. There was a need for a brief, selfadministered tool that could be used to screen for the presence of NP; thus identification (ID) pain questionnaire was developed. ${ }^{11}$

Identification pain questionnaire is a six-item screening questionnaire, including five sensory descriptor items and one item related to joint pain. The item related to joint pain identifies NNP. The ID pain tool seems to reveal the presence of neuropathic component of pain accurately. ${ }^{12}$ On the other hand, this questionnaire includes a body figure on which the patient can mark the location of pain; however, this marking has no effect on scoring of the questionnaire and may help the clinician about the management of symptoms. Because of being a self-administered and simple tool, ID pain questionnaire has been translated into several languages. ${ }^{12-15}$ Therefore, in this study, we aimed to assess the validity and reliability of a Turkish version of the ID pain (ID pain-T) questionnaire in Turkish patients.

\section{PATIENTS AND METHODS}

This cross-cultural adaptation and validation study was conducted at Ufuk University Faculty of Medicine Hospital between November 2016 and November 2017. ID pain questionnaire was adapted to Turkish population by using the recommended guidelines for cross-cultural adaptation. ${ }^{16}$ First, four native Turkish-speaking physicians, a construction engineer and a teacher translated the English ID pain questionnaire into Turkish and then the Turkish questionnaire was back-translated into English by a native English speaker who was blinded to original questionnaire and used Turkish fluently. The most accurate Turkish translation was chosen by authors. A pilot group including 30 patients (12 males, 18 females; 54.0 \pm 14.7 years; range, 26 to 80 years) with pain complaints were asked to complete the chosen questionnaire and asked if they had any difficulties in understanding the questions. A final revision was made to assess the appropriateness of the translated questionnaire. The study protocol was approved by the Ufuk University Ethics Committee. A written informed consent was obtained from each patient. The study was conducted in accordance with the principles of the Declaration of Helsinki.

The study included 194 patients of which 100 (34 males, 66 females; mean age 59.8 14.3 years; range, 28 to 88 years) were diagnosed as NP and 94 (31 males, 63 females; mean age $47.2 \pm 16.5$ years; range, 20 to 78 years) were diagnosed as NNP. Patients with a pain complement in one or more anatomical location for more than three months and who had not participated in another pain study within the past 30 days were included. Patients with mixed-type pain, cancer pain, headaches, substance abuse, severe depression or fibromyalgia syndrome were excluded. Musculoskeletal and neurological examinations of the patients were performed. NP was determined by the Douleur Neuropathique 4 (DN4) questionnaire. The DN4 questionnaire was originally developed for NP diagnosis, consisting of seven items related to symptoms and three related to clinical examination. ${ }^{5}$ For each item, a score of " 1 " is given if the response is "yes" and a score of " 0 " is given if it is "no". The patient is considered to have NP if the total score is calculated to be 4 or more. The reliability and validity study of Turkish version of DN4 was performed by Unal-Cevik et al. ${ }^{17}$

Eligible subjects completed the ID pain- $\mathrm{T}$ questionnaire by themselves in a waiting room and returned it in a sealed envelope. ID pain-T questionnaire consists of six items: "Yes" answers to questions 1-5 were given a score of 1 , while "yes" answer to question 6 scored -1. "No" answers to questions 1-5 were given a score of 0 , while "yes" answer to question 6 scored $0 .{ }^{18}$

\section{Statistical analysis}

Socio-demographic and clinical characteristics of patients were summarized for the whole sample (NP and NNP groups) using frequency (\%) for categorical variables and mean (standard deviation) for continuous variables. All data for normality were tested by using the KolmogorovSmirnov test. To compare the differences between the groups, the Mann-Whitney U test was used.

The ID pain-T questionnaire responses were collected in two sessions with at last three days between the sessions for pre- and postassessment. Reliability of ID pain-T questionnaire 


\begin{tabular}{|c|c|c|c|c|c|c|c|}
\hline & \multicolumn{3}{|c|}{ Neuropathic pain (NP) group $(\mathrm{n}=100)$} & \multicolumn{3}{|c|}{ Non-neuropathic pain (NNP) group ( $\mathrm{n}=94)$} & \multirow[b]{2}{*}{$p$} \\
\hline & $\mathrm{n}$ & $\%$ & Mean \pm SD & $\mathrm{n}$ & $\%$ & Mean \pm SD & \\
\hline Age (year) & & & $59.8 \pm 14.3$ & & & $47.2 \pm 16.5$ & $0.001^{* *}$ \\
\hline $\begin{array}{l}\text { Gender } \\
\text { Female } \\
\text { Male }\end{array}$ & $\begin{array}{l}66 \\
34\end{array}$ & & & $\begin{array}{l}63 \\
31\end{array}$ & & & 0.881 \\
\hline $\begin{array}{l}\text { Education level } \\
\text { Low ( } \leq 8 \text { years) } \\
\text { High ( }>8 \text { years) }\end{array}$ & $\begin{array}{l}27 \\
73\end{array}$ & $\begin{array}{l}27 \\
73\end{array}$ & & $\begin{array}{c}3 \\
91\end{array}$ & $\begin{array}{c}3.2 \\
86.8\end{array}$ & & $0.001^{* *}$ \\
\hline $\begin{array}{l}\text { Occupation } \\
\text { Employed } \\
\text { Unemployed }\end{array}$ & $\begin{array}{l}34 \\
66\end{array}$ & $\begin{array}{l}34 \\
66\end{array}$ & & $\begin{array}{l}63 \\
31\end{array}$ & $\begin{array}{l}67 \\
33\end{array}$ & & $\begin{array}{l}0.001^{* *} \\
0.005^{* * *}\end{array}$ \\
\hline Duration of pain (years) & & & $4.3 \pm 3.4$ & & & $2.7 \pm 1.3$ & $0.005^{* *}$ \\
\hline $\begin{array}{l}\text { Medication use for pain relief } \\
\text { Medication } \\
\text { No medication }\end{array}$ & $\begin{array}{l}86 \\
14\end{array}$ & $\begin{array}{l}86 \\
14\end{array}$ & & $\begin{array}{l}51 \\
43 \\
\end{array}$ & $\begin{array}{l}54.3 \\
45.7 \\
\end{array}$ & & $0.001^{* *}$ \\
\hline
\end{tabular}

was tested by internal consistency and test-retest reliability. Internal consistency was evaluated by determining intraclass correlation coefficient (ICC) with 95\% confidence interval, ranged between 0 and 1 . Results more than 0.70 were accepted for reliability. ${ }^{19,20}$ To determine the internal consistency of the six items of the ID pain-T questionnaire, Cronbach's alpha $(\alpha)$ coefficient was computed for both pre- and post-assessment of the questionnaire.

Median (interquartile range) of total scores for ID pain-T questionnaire were calculated. Then, receiver operating characteristics curve (ROC) analysis was used to assess the discriminant validity of ID pain-T questionnaire for determining NP. In addition to the ROC curve, the area under the curve (AUC) was calculated to provide the predictive power of the questionnaire for the diagnosis of NP.

\section{RESULTS}

Demographic and clinical characteristics of the patients are shown in Table 1 . The etiology of pain in all study population is shown in Table 2 . The majority of patients had lumbar radiculopathy $(\mathrm{n}=34,17.5 \%)$ and cervical radiculopathy $(\mathrm{n}=31,15.9 \%)$ in NP group (Table 2$)$.

The most frequent score in NP group was $3(33 \%)$ and the most frequent scores in NNP group were -1 (26\%) and 2 (26\%) (Table 3). There were statistically significant differences for all ID pain- $T$ questionnaire total scores between the groups $(p<0.0001)$ (Table 3$)$.

The ID pain-T questionnaire was reliable for overall sample with Cronbach's $\alpha$ coefficients of 0.701 (pre-assessment) and 0.688 (post-assessment) (Table 4). The ICC between pre- and post-ID pain-T questionnaire total scores for overall sample was 0.975 (0.965-0.980); whereas, for NP and NNP groups, the ICC were

Table 2. Etiology of pain in study patients

\begin{tabular}{lcc}
\hline & $\mathrm{n}$ & $\%$ \\
\hline Neuropathic pain (n=100) & & \\
Lumbar radiculopathy & 34 & 17.5 \\
Cervical radiculopathy & 31 & 15.9 \\
Polyneuropathy & 18 & 9.3 \\
Post-herpetic neuralgia & 10 & 5.1 \\
Carpal tunnel syndrome & 4 & 2.0 \\
Post-stroke pain & 2 & 1.0 \\
Neuralgia paresthetica & 1 & 0.5 \\
Non-neuropathic pain (n=94) & & \\
Osteoarthritis & 21 & 10.82 \\
Cervical radiculopathy & 20 & 10.3 \\
Lumbar radiculopathy & 19 & 9.79 \\
Mechanical neck or back pain & 14 & 7.21 \\
Tendinitis & 8 & 4.1 \\
\hline
\end{tabular}


Table 3. Turkish version of identification pain questionnaire scores classified according to neuropathic and non-neuropathic pain groups

\begin{tabular}{|c|c|c|c|c|c|}
\hline \multirow[b]{2}{*}{ Score } & \multicolumn{2}{|c|}{ Neuropathic pain group $(n=100)$} & \multicolumn{2}{|c|}{ Non-neuropathic pain group $(n=94)$} & \multirow[b]{2}{*}{$p^{*}$} \\
\hline & $\mathrm{n}$ & $\%$ & $\mathrm{n}$ & $\%$ & \\
\hline-1 & 0 & 0 & 26 & 27.7 & $0.001 \dagger$ \\
\hline 0 & 5 & 5 & 18 & 19.1 & $0.001 \dagger$ \\
\hline 1 & 6 & 6 & 24 & 25.5 & $0.001 \dagger$ \\
\hline 2 & 17 & 17 & 26 & 27.7 & $0.001 \dagger$ \\
\hline 3 & 33 & 33 & 0 & 0 & $0.001 \dagger$ \\
\hline 4 & 24 & 24 & 0 & 0 & $0.001 \dagger$ \\
\hline 5 & 15 & 15 & 0 & 0 & $0.001 \dagger$ \\
\hline
\end{tabular}

0.927 (0.891-0.951) and 0.961 (0.941-0.974) respectively (Table 4). Cronbach's $\alpha$ for the pre-assessment were $0.701,0.423$, and 0.381 for the overall sample, NP, and NNP groups, respectively. Similar values of Cronbach's $\alpha$ were observed for the post-assessment measures of ID pain-T questionnaire.

The medians for the ID pain-T questionnaire total scores were 3.10 (range, 0-5) and 0.53 (range, -1-2) in the NP and NNP groups, respectively $(p<0.001)$. There were 88 patients who were diagnosed as NP with a score of $\geq 2$ both clinically and with ID pain-T questionnaire, giving a sensitivity of $77.2 \%$ (Table 5). In comparison, there were 68 patients who were diagnosed as NNP both clinically and with ID pain-T questionnaire, giving a specificity of $85 \%$ (Table 5). Total scores of ID pain-T questionnaire in study population were high, which correlated with the total scores in DN4 questionnaire (construct validity $\mathrm{r}=0.61$,

Table 4. Test-retest and its internal consistency

\begin{tabular}{lccc}
\hline & Overall sample $(\mathrm{n}=194)$ & Neuropathic pain group $(\mathrm{n}=100)$ & Non-neuropathic pain group ( $\mathrm{n}=94)$ \\
\hline $\begin{array}{l}\text { Total Scale score: } \\
\text { test-retest reliability }\end{array}$ & ICC $(95 \%)$ & ICC $(95 \%)$ & ICC (95\%) \\
\hline & $0.975(0.965-0.980)$ & $0.927(0.891-0.951)$ & $0.961(0.941-0.974)$ \\
\hline Pre-assessment & Cronbach's $\alpha$ & Cronbach's $\alpha$ & Cronbach's $\alpha$ \\
Post-assessment & 0.701 & 0.423 & 0.381 \\
\hline
\end{tabular}

ICC (95 CI\%): Intraclass correlation coefficient (95\% confidence interval) for examining test-retest reliability of the questionnaire total score; Cronbach's $\alpha$ (alpha): Coefficient used to examine internal consistency of Turkish version of identification pain questionnaire.

Table 5. Statistical analysis comparing clinical diagnosis and Turkish version of identification pain questionnaire for neuropathic pain

\begin{tabular}{|c|c|c|c|c|c|}
\hline & \multicolumn{2}{|c|}{ Neuropathic pain group $(n=100)$} & \multicolumn{2}{|c|}{ Non-neuropathic pain group $(n=94)$} & \multirow[b]{2}{*}{$p^{*}$} \\
\hline & $\mathrm{n}$ & $\%$ & $\mathrm{n}$ & $\%$ & \\
\hline $\begin{array}{l}\text { Neuropathic pain } \\
\quad(\text { ID pain-T total score } \geq 2 \text { ) }\end{array}$ & 88 & 77.2 & 26 & 22.8 & \multirow{2}{*}{$<0.001 \dagger$} \\
\hline $\begin{array}{l}\text { Non-neuropathic pain } \\
\quad(\text { ID pain-T total score }<2 \text { ) }\end{array}$ & 12 & 15 & 68 & 85 & \\
\hline
\end{tabular}




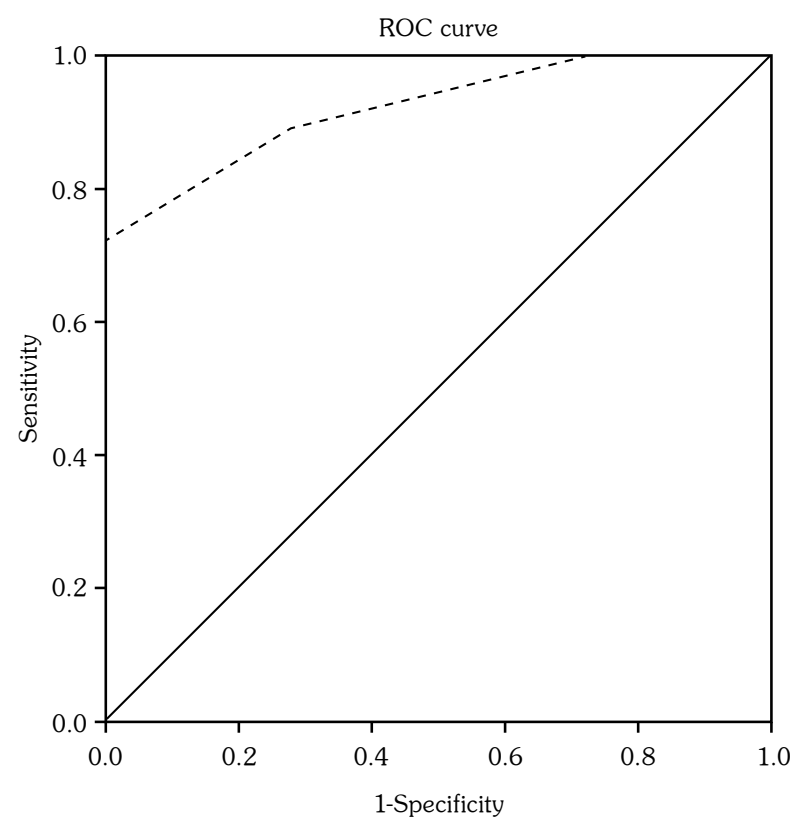

Figure 1. Receiver operating characteristics curve analysis: Plot of sensitivity area versus 1-specifity for Turkish version of identification pain questionnaire.

$p=0.001$ for NP group and $r=0.61, p=0.001$ for NNP group). When the ID pain-T questionnaire validity was evaluated with ROC curve and AUC analysis, a total score $\geq 2$ points in ID pain- $T$ questionnaire was found to be very effective to discriminate between neuropathic and nonneuropathic patients (AUC 0.92) (Figure 1).

\section{DISCUSSION}

Neuropathic pain diagnosis is challenging both for physicians and patients because of the subjective symptoms, absence of a standardized identification tool and limitation of the studies about the gold standard for the diagnosis of this pain type. Clinicians who do not have specific interest in pain, family practitioners and general healthcare givers need a short, simple and accurate tool for identifying NP. As an advantage, ID pain questionnaire has excellent brevity and simplicity because of taking only a few minutes and not needing any special physical examination. The previous studies demonstrated that ID pain questionnaire has high sensitivity and specificity for the diagnosis of NP. ${ }^{12}$ In this study, we validated the ID pain-T questionnaire to be used in Turkish speaking NP patients.
A validation study for the Spanish version of ID pain questionnaire included 145 (51.2\%) subjects with NP and 138 (48.8\%) with NNP and demonstrated that with a cut-off value of $\geq 3$ points, the AUC value was 0.89 with a sensitivity of $81 \%$ and specificity of $84 \% .{ }^{12}$ Another study for the Arabic version of ID pain questionnaire included 375 patients (153 with NP and 222 with NNP) and demonstrated that with a cut-off value of $\geq 2$ points, the AUC value was 0.808 with a sensitivity of $84.3 \%$ and specificity of 73.9\% (Cronbach $\alpha$ coefficient value 0.506). ${ }^{21}$ The Taiwan version of ID pain questionnaire included 317 patients and demonstrated that the reliability and consistency of the questionnaire were acceptable, with a Cronbach's $\alpha$ value of 0.6; they also calculated an optimal cut-off score of $\geq 2$ for determining NP with 77\% sensitivity and 74\% specificity. ${ }^{22}$ In the Chinese ID pain questionnaire study conducted in Hong Kong with a cut-off score of $\geq 3$, an $81 \%$ specificity and $65 \%$ sensitivity were found with a Cronbach's $\alpha$ coefficient of $0.76 .{ }^{23}$ Similar to these studies, our results suggested that ID pain-T questionnaire is a reliable and valuable tool to detect NP. When Cronbach's $\alpha$ coefficient was assessed to test for reliability, a score of 0.701 was found for this current study; it is well-known that Cronbach's $\alpha$ coefficient values above 0.7 are considered as good reliability for ID pain questionnaires. ${ }^{19,20}$ On the other hand, the ICC coefficient between pre- and post-ID pain-T questionnaire total scores also showed a high level of test-retest reliability. Further, with an excellent value of 0.92 for AUC, a good diagnostic value was indicated. Most importantly, with a cut-off value $\geq 2$, ID pain- $T$ questionnaire demonstrated a sensitivity of $77.2 \%$ and specificity of $85 \%$.

There are a number of questionnaires for screening patients with NP. However, inappropriate medication use may be seen in clinics where the availability of a pain physician is difficult. So, a questionnaire is needed which can be used by a general practitioner to correctly diagnose the pain type. As a power of our study, ID pain-T questionnaire can be administered by the patient himself with no need of a pain physician or another tool. On the other hand, a limitation of our study was that the demographic data between NP and NNP groups differed in terms of age, education level, occupation, duration of pain and medication use for pain relief. 
In conclusion, the ID pain-T questionnaire assessed in the present study is a valid and reliable self-administered questionnaire to identify $\mathrm{NP}$ in Turkish patients. ID pain-T questionnaire is advantageous in the primary care settings and can be filled without a physician assistance; thus ID pain-T questionnaire is promising for being used in screening and diagnosis of various neuropathies in clinical settings.

\section{Declaration of conflicting interests}

The authors declared no conflicts of interest with respect to the authorship and/or publication of this article.

\section{Funding}

The authors received no financial support for the research and/or authorship of this article.

\section{REFERENCES}

1. Jensen TS, Baron R, Haanpää M, Kalso E, Loeser JD, Rice AS, et al. A new definition of neuropathic pain. Pain 2011;152:2204-5.

2. Dieleman JP, Kerklaan J, Huygen FJ, Bouma PA, Sturkenboom MC. Incidence rates and treatment of neuropathic pain conditions in the general population. Pain 2008;137:681-8.

3. IASP Task Force in Taxonomy. Pain terms: A current list with definitions and notes on usage. In: Merksey $\mathrm{H}$, Bogduk N, editors. Classification of chronic pain syndromes and definitions of pain terms. 2nd ed. Seattle: IASP Press; 1994. p. 206-13.

4. Treede RD, Jensen TS, Campbell JN, Cruccu G, Dostrovsky JO, Griffin JW, et al. Neuropathic pain: redefinition and a grading system for clinical and research purposes. Neurology 2008;70:1630-5.

5. Bouhassira D, Attal N, Alchaar H, Boureau F, Brochet $\mathrm{B}$, Bruxelle $\mathrm{J}$, et al. Comparison of pain syndromes associated with nervous or somatic lesions and development of a new neuropathic pain diagnostic questionnaire (DN4). Pain 2005;114:29-36.

6. Hansson P. Neuropathic pain: clinical characteristics and diagnostic workup. Eur J Pain 2002;6:47-50.

7. Jensen TS, Gottrup H, Sindrup SH, Bach FW. The clinical picture of neuropathic pain. Eur J Pharmacol 2001;429:1-11.

8. Harden N, Cohen M. Unmet needs in the management of neuropathic pain. J Pain Symptom Manage 2003;25:12-7.

9. Dworkin RH, O'Connor AB, Backonja M, Farrar JT, Finnerup NB, Jensen TS, et al. Pharmacologic management of neuropathic pain: evidence-based recommendations. Pain 2007;132:237-51.

10. Finnerup NB, Sindrup SH, Jensen TS. The evidence for pharmacological treatment of neuropathic pain. Pain 2010;150:573-81.

11. Portenoy R. Development and testing of a neuropathic pain screening questionnaire: ID Pain. Curr Med Res Opin 2006;22:1555-65.

12. Gálvez R, Pardo A, Cerón JM, Villasante F, Aranguren JL, Saldaña MT, et al. Linguistic adaptation into Spanish and psychometric validation of the ID-Pain questionnaire for the screening of neuropathic pain. Med Clin (Barc) 2008;131:572-8.

13. Gudala K, Ghai B, Bansal D. Usefulness of four commonly used neuropathic pain screening questionnaires in patients with chronic low back pain: a cross-sectional study. Korean J Pain 2017;30:51-58.

14. Kitisomprayoonkul W. Validation study of the Thai ID Pain Scale. J Med Assoc Thai 2011;94:610-5.

15. Li J, Feng Y, Han J, Fan B, Wu D, Zhang D, et al. Linguistic adaptation, validation and comparison of 3 routinely used neuropathic pain questionnaires. Pain Physician 2012;15:179-86.

16. Beaton DE, Bombardier C, Guillemin F, Ferraz MB. Guidelines for the process of cross-cultural adaptation of self-report measures. Spine (Phila Pa 1976) 2000;25:3186-91.

17. Unal-Cevik I, Sarioglu-Ay S, Evcik D. A comparison of the DN4 and LANSS questionnaires in the assessment of neuropathic pain: validity and reliability of the Turkish version of DN4. J Pain 2010;11:1129-35.

18. McCarberg BH, Billington R. Consequences of neuropathic pain: quality-of-life issues and associated costs. Am J Manag Care 2006;12:263-8.

19. Eechaute C, Vaes P, Van Aerschot L, Asman S, Duquet $\mathrm{W}$. The clinimetric qualities of patientassessed instruments for measuring chronic ankle instability: a systematic review. BMC Musculoskelet Disord 2007;8:6.

20. Nørholm V, Bech P. The WHO Quality of Life (WHOQOL) Questionnaire: Danish validation study. Nord J Psychiatry 2001;55:229-35.

21. Abu-Shaheen A, Yousef S, Riaz M, Nofal A, Khan S, Heena $\mathrm{H}$. Validity and reliability of Arabic version of the ID Pain screening questionnaire in the assessment of neuropathic pain. PLoS One 2018;13:e0192307.

22. Yang CC, Ro LS, Tsai YC, Lin KP, Sun WZ, Fang WT, et al. Development and validation of a Taiwan version of the ID Pain questionnaire (ID Pain-T). J Chin Med Assoc 2018;81:12-17.

23. Chan A, Wong S, Chen PP, Tsoi TH, Lam J, Ip WY, et al. Validation study of the Chinese Identification Pain Questionnaire for neuropathic pain. Hong Kong Med J 2011;17:297-300. 